\title{
Efficacy and safety of etanercept in moderate-to-severe asthma: a randomised, controlled trial
}

\author{
S.T. Holgate*, M. Noonan\# ${ }^{\#}$ P. Chanez ${ }^{\star}$, W. Busse ${ }^{+}$, L. Dupont ${ }^{\S}$, I. Pavord ${ }^{f}$,

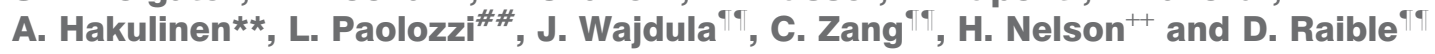

ABSTRACT: Increased tumour necrosis factor- $\alpha$ levels have been observed in bronchial biopsies and induced sputum from subjects with severe asthma. We investigated etanercept (ETN) as a therapeutic option for treating moderate-to-severe persistent asthma.

In this 12-week, randomised, double-blind, placebo-controlled, phase 2 trial, subjects $(n=132)$ with moderate-to-severe persistent asthma received subcutaneous injections of 25 mg ETN or placebo twice weekly, and were evaluated at baseline, and at weeks 2, 4, 8 and 12. The primary end-point was the change from baseline to week 12 in pre-bronchodilator forced expiratory volume in $1 \mathrm{~s}$ (FEV1) \% predicted. Secondary end-points included morning peak expiratory flow, FEV1 \% pred, Asthma Control Questionnaire (5-item version), asthma exacerbations, provocative concentration of methacholine causing a $20 \%$ decrease in FEV 1 , and the Asthma Quality of Life Questionnaire.

No significant differences were observed between ETN and placebo for any of the efficacy endpoints. ETN treatment was well tolerated, with no unexpected safety findings observed during the study.

Clinical efficacy of ETN was not shown in subjects with moderate-to-severe persistent asthma over 12 weeks. However, ETN treatment was a well-tolerated therapy. Studies in specific subsets of patients with asthma with longer-term follow-up may be needed to fully evaluate the clinical efficacy of ETN in this population.

KEYWORDS: Asthma, etanercept, forced expiratory volume

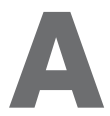
sthma is a chronic inflammatory disorder of the airways characterised by airflow obstruction, hyperresponsiveness and remodelling, leading to variable airflow obstruction $[1,2]$. This inflammatory disorder involves the recruitment of eosinophils, mast cells, T-helper type 2 lymphocytes, neutrophils and macrophages, which is regulated by local release of autacoid mediators, cytokines and chemokines [3, 4].

The first line of therapy for asthma includes leukotriene modifiers and inhaled corticosteroids used alone or in combination with long-acting $\beta_{2}$-adrenoceptor agonists (LABAs); however, $\sim 5-15 \%$ of subjects with severe disease either do not respond or respond incompletely to this therapy [5-7]. For subjects with severe asthma, treatment with drugs that modify the immune response, or therapies with monoclonal antibodies directed to immunoglobulin (Ig)E or interleukin-5 are effective, although efficacy appears to be restricted to specific patient subtypes $[8,9]$.
Tumour necrosis factor (TNF)- $\alpha$ is an effective therapeutic target in chronic inflammatory disorders [10]. This cytokine is predominantly produced by lymphocytes, macrophages and mast cells. TNF- $\alpha$ produces its pleotropic effects by interacting with two receptor subtypes, p55 and p75, and it augments inflammatory responses through multiple mechanisms, including the promotion of leukocyte adhesion and enhanced mediator release [11].

Increased levels of TNF- $\alpha$ have been observed in bronchial biopsies and induced sputum from subjects with severe asthma [12-15]. Monocytes and macrophages of subjects with asthma have also been shown to have higher TNF- $\alpha$ production compared with these cells from subjects without asthma [16]. Additionally, inhalation of TNF- $\alpha$ in normal individuals and those with asthma has been shown to increase airway hyperresponsiveness and cause an influx of neutrophils into the airways [17, 18]. Thus,

\section{AFFLLIATIONS}

*School of Medicine, University of Southampton, Southampton, ${ }^{t}$ Dept of Respiratory Medicine,

Thoracic Surgery and Allergy, University Hospitals of Leicester NHS Trust, Glenfield Hospital, Leicester, UK.

\#Allergy Associates Research Center, Portland, OR, ${ }^{+}$Dept of Medicine, University of Wisconsin, Madison, WI,

"Pfizer Inc., Collegeville, PA, ${ }^{++}$National Jewish Health, Denver, CO, USA.

'Département des Maladies Respiratoires, Université de la Méditerranée, Marseille,

\#\#Pfizer Inc., Paris, France.

${ }^{\text {s}}$ Dept of Respiratory Medicine,

University Hospital Gasthuisberg, KU Leuven, Leuven, Belgium.

${ }^{*}$ Clinical Research Institute $\mathrm{HUCH}$ (Helsinki University Central Hospital), Skin and Allergy Hospital, Helsinki, Finland.

CORRESPONDENCE

S.T. Holgate

III Division

Mail Point 810

Level $F$

South Block

Southampton General Hospital

Southampton

Hampshire

S016 6YD

UK

E-mail: sth@soton.ac.uk

Received:

April 232010

Accepted after revision:

Oct 262010

First published online:

Nov 252010

European Respiratory Journal

Print ISSN 0903-1936

Online ISSN 1399-3003 
TNF- $\alpha$ may play a sentinel role in maintaining the inflammatory state in subjects with asthma, especially those whose asthma is refractory to treatment with inhaled corticosteroids $[19,20]$.

Several clinical studies have examined the efficacy and safety of recombinant antibodies that bind and neutralise the soluble TNF- $\alpha$ homotrimer and its membrane-bound precursor [21]. Etanercept (ETN) is a genetically engineered recombinant protein consisting of two molecules of the extracellular portion of p75 TNF receptor, fused to the Fc portion of a human IgG1 [22]. ETN binds both TNF-á and lymphotoxin-á with high affinity.

In an open-label, pilot study, HOWARTH et al. [14] found that in subjects $(n=17)$ with severe asthma who received $25 \mathrm{mg}$ ETN twice weekly as an add-on therapy for 12 weeks, ETN was associated with improvements in lung function, asthma symptoms and bronchial hyperresponsiveness. In a subsequent 10-week, double-blind, placebo-controlled trial of ETN in subjects $(n=30)$ with refractory asthma, similar clinical improvements occurred, including improved asthma-related quality of life [23]. However, in a small $(n=39)$ randomised, placebo-controlled trial, ETN did not have significant effects in patients with moderate-to-severe asthma [24].

The efficacy of other anti-TNF therapies in subjects with moderate-to-severe asthma has also not been convincing. A recent study evaluating infliximab failed to demonstrate clinical efficacy for the primary end-point in subjects with moderate asthma [3]. Similarly, no significant differences between placebo and anti-TNF- $\alpha$ biologic golimumab were observed in subjects with uncontrolled, severe, persistent asthma after 24 weeks of treatment, although a subgroup with more reversible airflow obstruction and upper airway disease did appear to respond in a dose-dependent manner [25].

These data suggest that severe asthma is a heterogeneous disease consisting of several subphenotypes [25, 26]. As in other complex diseases, substratification of patients with asthma according to disease phenotype and comorbidities may lead to more individualised therapies [26].

Because outcomes in previous trials of ETN in subjects with moderate-to-severe asthma have been so variable [14, 23, 24], this study was designed to provide additional data from a larger number of subjects on the effect of ETN in this population.

\section{METHODS AND MATERIALS Study design}

This was a 12-week, randomised, parallel, double-blind, placebo-controlled, worldwide phase 2 trial evaluating the efficacy and safety of ETN in subjects with moderate-to-severe persistent asthma conducted at 36 sites (ClinicalTrials.gov identifier NCT00141791). Clinical evaluations were performed at screening and baseline, at weeks 2, 4, 8 and 12, and during a follow-up period of 2-4 weeks. Eligible subjects were randomised to subcutaneous injection of either $25 \mathrm{mg}$ ETN or placebo twice weekly.

This study was undertaken in accordance with the ethical principles of the Declaration of Helsinki. The protocol and its amendments received independent ethics committee or institutional review-board approval before site initiation and recruitment of subjects. All elements of informed consent were explained to eligible subjects, and adequate time was allowed for questions and for subjects to make voluntary decisions. No subject underwent procedures specific to the protocol until he or she had signed and dated an approved informed consent form.

\section{Subjects}

Subjects (aged 18-70 yrs) were included in the study if they had been diagnosed with moderate-to-severe persistent asthma as defined by the National Heart, Lung and Blood Institute (NHLBI) [27] $\geqslant 1$ yr before randomisation. All subjects demonstrated $\geqslant 9 \%$ actual reversibility from the prebronchodilator baseline forced expiratory volume in $1 \mathrm{~s}$ (FEV1) with inhaled albuterol during screening or at baseline, and had an FEV1 of $50-80 \%$ predicted $\geqslant 6 \mathrm{~h}$ after a short-acting $\beta_{2-}$ agonist or $12 \mathrm{~h}$ after a LABA at screening or baseline. Subjects were also required to: have a mean score of $\geqslant 2$ on the Asthma Control Questionnaire (5-item version; ACQ-5) [28], be taking a high-dose inhaled corticosteroid $\left(\geqslant 1,000 \mu \mathrm{g} \cdot\right.$ day $^{-1}$ beclomethasone-chlorofluorocarbons, $500 \mu \mathrm{g} \cdot$ day $^{-1}$ beclomethasone-hydrofluoroalkane, $500 \mu \mathrm{g} \cdot$ day $^{-1}$ fluticasone or $1,000 \mu \mathrm{g} \cdot$ day $^{-1}$ budesonide, or equivalent); and be receiving stable doses of their current medications for asthma $\geqslant 4$ weeks prior to randomisation. Females needed to have a negative pregnancy test at screening, and all sexually active females and males were to use a medically acceptable contraceptive during the study.

Subjects were excluded from the study if they had: previous treatment with ETN, antibody to TNF- $\alpha$ or other TNF- $\alpha$ inhibitors; investigational biologic agents $\leqslant 3$ months prior to randomisation; any live (attenuated) vaccines $\leqslant 4$ weeks prior to randomisation; or were currently using cigarettes or cigars, or had a smoking history $>10$ pack-yrs. Also excluded from the study were subjects with: abnormal blood chemistry or haematology profiles; respiratory tract infection $\leqslant 4$ weeks before baseline; significant concurrent medical conditions at the time of screening, including chronic obstructive pulmonary disease, active infections or underlying disease, tuberculosis, uncontrolled hypertension, class III-IV or uncompensated congestive heart failure, multiple sclerosis, uncontrolled insulindependent diabetes mellitus, any rheumatologic disease, cancer or history of cancer, known HIV, presence of hepatitis $\mathrm{B}$ or C antigens; psychiatric illnesses; or history of drug or alcohol abuse.

The subjects were permitted to continue inhaled and oral corticosteroids ( $\leqslant 12.5 \mathrm{mg}$ prednisone or equivalent), inhaled LABAs, leukotriene antagonists, cromones, antihistamines, and allergen immunotherapy if the maintenance dose was stable for 3 months. Prohibited treatments included oral corticosteroids (>12.5 mg prednisone or equivalent), inhaled anticholinergics, theophylline, oral $\beta_{2}$-agonists, systemic immunosuppressive agents (methotrexate and cyclophosphamide), $\beta$-blockers, any live (attenuated) vaccine, and other TNF- $\alpha$ antagonists or biologics.

\section{Efficacy end-points}

The primary efficacy end-point was the change in prebronchodilator FEV1 \% pred from baseline to week 12. Secondary end-points included: morning pre-bronchodilator peak expiratory flow (PEF); FEV1 \% pred at weeks 2, 4 and 8; ACQ-5 score; provocative concentration of methacholine 


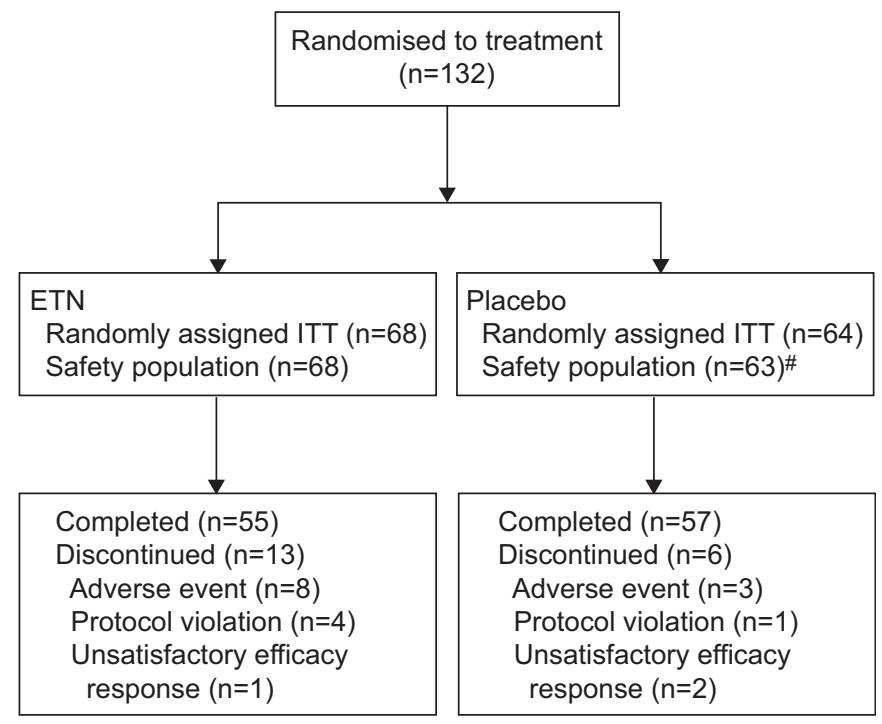

FIGURE 1. Subject disposition. ETN: etanercept; ITT: intent-to-treat population. \#: one subject randomised to placebo did not receive the study medication.

causing a 20\% decrease in FEV1 (PC20), measured by either the tidal breathing method or the dosimeter method (site preference); Asthma Quality of Life Questionnaire (AQLQ) score [29]; and asthma exacerbations, which were defined as unscheduled visits requiring de novo systemic corticosteroids or an increase in the dose of oral corticosteroids, an emergency room visit, or hospitalisation.

\section{Statistical analysis}

60 patients per treatment group yielded $\sim 90 \%$ power to detect a $10 \%$ point difference in the change of FEV1 \% pred from baseline between the ETN and placebo groups, assuming the standard deviation of the change of FEV1 from baseline to week 12 was $16 \%$, and a two-sided t-test was used to compare at a significance level of $\mathrm{p}<0.05$.

Efficacy analysis was performed on the intent-to-treat (ITT) population, which included all randomised subjects and was the primary population for efficacy analysis. Safety was analysed for all subjects who received at least one dose of study medication.

Change from baseline in FEV1 \% pred was calculated at each time-point and analysed using an ANCOVA, with baseline FEV1 measurement used as a covariate and treatment group as a factor. Paired t-tests were used for the comparisons of changes from baseline within treatment groups for the ITT population at each time-point.

Secondary efficacy end-points were analysed using ANCOVA, with the corresponding baseline measurement for the variable used as the covariate. A "last observation carried forward" approach was used for missing values for analysis of the ITT population.

\section{RESULTS}

\section{Subject disposition}

In total, 132 subjects were randomised (ITT population); however, one subject randomised to placebo did not receive study medication. Therefore, 131 subjects were included in the safety analysis. The disposition of all subjects randomised to treatment is shown in figure 1. No significant differences in baseline and demographic characteristics were observed between treatment groups for the safety population (table 1). At the time of enrolment, $90 \%$ of the subjects taking ETN and $89 \%$ of the subjects receiving placebo were using inhaled LABAs.

\section{Clinical efficacy}

No statistically significant differences between ETN and placebo were shown for any of the primary or secondary end-points. At week 12, the adjusted mean \pm SE changes from baseline in FEV1 \% pred were $3.0 \pm 1.3$ and $1.7 \pm 1.3 \%$ for the ETN and placebo groups, respectively. No significant changes from baseline were observed between treatments for the primary efficacy end-point at weeks 2, 4 or 8 (fig. 2).

\begin{tabular}{|c|c|c|c|}
\hline \multicolumn{4}{|c|}{$\begin{array}{l}\text { TABLE } 1 \text { Subject demographic and baseline } \\
\text { characteristics (safety population) }\end{array}$} \\
\hline Characteristic & ETN & Placebo & p-value \\
\hline Subjects $n$ & 68 & 63 & \\
\hline Age yrs & $45.94 \pm 12.6$ & $48.67 \pm 12.3$ & $0.21^{\circ}$ \\
\hline Sex & & & $1.00^{+}$ \\
\hline Female & $46(67.7)$ & $42(66.7)$ & \\
\hline Male & $22(32.4)$ & 21 (33.3) & \\
\hline Ethnic origin & & & $0.58^{+}$ \\
\hline White & 57 (83.8) & $52(82.5)$ & \\
\hline Black or African American & $7(10.3)$ & $7(11.1)$ & \\
\hline Asian & $2(2.9)$ & 0 & \\
\hline Other & $2(2.9)$ & $4(6.4)$ & \\
\hline Body mass index $\mathrm{kg} \cdot \mathrm{m}^{-2}$ & $30.7 \pm 7.4$ & $30.1 \pm 5.8$ & $0.57^{+}$ \\
\hline Inhaled corticosteroids & $68(100.0)$ & $63(100.0)$ & \\
\hline Oral corticosteroids & $10(14.7)$ & $10(15.9)$ & $1.00^{+}$ \\
\hline LABA & $61(89.7)$ & $56(88.9)$ & $1.00^{+}$ \\
\hline $\begin{array}{l}\text { History of environmental } \\
\text { allergy }\end{array}$ & $47(69)$ & $47(75)$ & $0.56^{+}$ \\
\hline \multicolumn{4}{|l|}{ Pulmonary status at baseline } \\
\hline Actual FEV 1 L & $2.09 \pm 0.7$ & $2.02 \pm 0.61$ & $0.56^{\circ}$ \\
\hline FEV $1 \%$ pred & $65.3 \pm 12.9$ & $64.5 \pm 11.7$ & $0.71^{\circ}$ \\
\hline FEV1 reversibility \% & $22.7 \pm 11.0$ & $21.4 \pm 10.4$ & $0.49^{\circ}$ \\
\hline Morning PEF L. $\min ^{-1}$ & $299.7 \pm 103.2$ & $291.6 \pm 105.6$ & $0.67^{\circ}$ \\
\hline Methacholine $\mathrm{PC}_{20} \# \mathrm{mg} \cdot \mathrm{mL}^{-1}$ & $0.6(0.1-8)$ & $1.1(0.1-16)$ & $0.31^{\#}$ \\
\hline ACQ-5 score & $2.9 \pm 0.9$ & $2.8 \pm 0.9$ & $0.47^{\circ}$ \\
\hline $\begin{array}{l}\text { Rescue medications } \\
\text { puffs } \cdot \text { day }^{-1}\end{array}$ & $2.9 \pm 3.4$ & $2.6 \pm 2.8$ & $0.62^{\circ}$ \\
\hline
\end{tabular}

Data are presented as mean $\pm \mathrm{SD}, \mathrm{n}(\%)$ or geometric mean (range), unless otherwise stated. 16 etanercept (ETN) and 12 placebo subjects completed methacholine challenge testing at baseline. Methacholine challenge testing was required in the protocol, unless contraindicated by local guidelines. LABA: longacting $\beta_{2}$-adrenoreceptor agonist; FEV1: forced expiratory volume in $1 \mathrm{~s} ; \%$ pred: \% predicted; PEF: peak expiratory flow; $\mathrm{PC} 20$ : provocative concentration causing a $20 \%$ decrease in FEV 1 ; ACQ-5: Asthma Control Questionnaire (5-item version). *: one-way ANOVA with treatment as factor based on log transformed data; ": one-way ANOVA with treatment as factor; ${ }^{+}$: Fisher's exact test. 


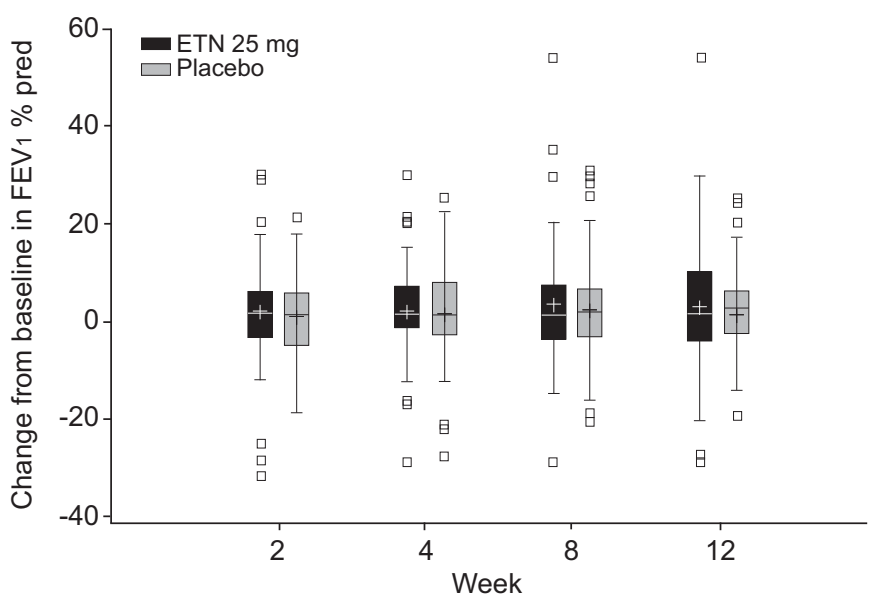

FIGURE 2. Box and whisker plots for change from baseline in forced expiratory volume in $1 \mathrm{~s}(\mathrm{FEV} 1) \%$ predicted in the intent-to-treat population (last observation carried forward). At week 12, the adjusted mean \pm SE change from baseline in FEV 1 $\%$ pred was $3.0 \pm 1.3 \%$ for the etanercept (ETN) group, compared with $1.7 \pm 1.3 \%$ for the placebo group. No significant difference between treatments was observed $(p=0.51)$. Similar findings were observed at weeks 2,4 , and 8 . Boxes represent interquartile range (IQR) and whiskers represent the minimum and maximum values with 1.5 IQR; —: median; +: mean; $\square$ : outliers.

Results for the secondary clinical efficacy end-points are provided in table 2. At week 12, morning PEF, ACQ-5 score, asthma exacerbations, methacholine PC20 and AQLQ score were not significantly different between subjects taking ETN and those taking placebo. Methacholine challenge testing was required for all subjects in the study, unless contraindicated by local guidelines. At baseline, only 16 ETN and 12 placebo subjects had PC20 determinations, and at week 12, only nine ETN and 12 placebo subjects completed the PC20 methacholine challenge.

Subgroup analyses were performed to examine whether there was greater efficacy of ETN among subjects who were taking oral corticosteroids at baseline had lower baseline FEV1 \% pred or greater FEV1 reversibility after administration of shortacting $\beta$-agonists. At week 12, no significant difference in FEV1 $\%$ pred between ETN and placebo subjects was observed among either those taking oral steroids or those who were not (data not shown). Likewise, no significant differences at week 12 between treatments were evident when the data were analysed by FEV1 $\%$ pred tertiles $(\leqslant 60 \%,>60 \%$ and $\leqslant 71.5 \%$, and $>71.5 \%$ pred; data not shown). Furthermore, no significant difference between ETN and placebo was shown for FEV1 reversibility when results were analysed by tertile subgroups ( $\leqslant 16 \%,>16 \%$ and $\leqslant 24 \%$, and and $>24 \%$ improvement from pre-bronchodilator FEV1 \% pred at baseline; data not shown).

\section{Safety}

The frequency of treatment-emergent adverse events (AEs) did not differ significantly between the treatments (table 3 ). Noninfectious AEs occurred in $41(60 \%)$ subjects in the ETN group compared with $31(49 \%)$ subjects in the placebo group $(\mathrm{p}=0.222$; table 3$)$. The most common noninfectious $\mathrm{AE}$ reported was injection site reaction, occurring more frequently in the ETN group than in the placebo group (36 versus $11 \%$, respectively; table 3).

\begin{tabular}{|c|c|c|c|c|}
\hline Efficacy end-point & ETN & Placebo & $\begin{array}{c}\text { Treatment } \\
\text { difference }^{\#} \\
\text { at week } 12 \\
\text { mean } \pm \mathrm{SE}\end{array}$ & p-value \\
\hline \multicolumn{5}{|l|}{ Morning PEF } \\
\hline \multicolumn{5}{|l|}{ Baseline } \\
\hline Subjects $n$ & 62 & 63 & & \\
\hline $\mathrm{PEF} L \cdot \mathrm{min}^{-1}$ & $299.7 \pm 103.2$ & $292.1 \pm 104.9$ & & \\
\hline Week 12 & & & $11.2 \pm 7.7$ & 0.149 \\
\hline Subjects $n$ & 67 & 64 & & \\
\hline PEF L. $\min ^{-1}$ & $300.7 \pm 104.4$ & $285.8 \pm 98.1$ & & \\
\hline \multicolumn{5}{|l|}{ ACQ-5 } \\
\hline \multicolumn{5}{|l|}{ Baseline } \\
\hline Subjects n & 68 & 64 & & \\
\hline ACQ-5 score & $2.9 \pm 0.9$ & $2.8 \pm 0.9$ & & \\
\hline Week 12 & & & $-0.3 \pm 0.2$ & 0.133 \\
\hline Subjects $n$ & 68 & 64 & & \\
\hline ACQ-5 score & $2.1 \pm 1.3$ & $2.3 \pm 1.3$ & & \\
\hline \multicolumn{5}{|l|}{ Asthma exacerbation } \\
\hline $\begin{array}{l}\text { Total events per } \\
\text { subject at week } 12\end{array}$ & $9 \pm 0.15$ & $6 \pm 0.11$ & NA & NA \\
\hline $\begin{array}{l}\text { Subjects with } \\
\text { exacerbations at } \\
\text { week } 12 \mathrm{n}(\%)\end{array}$ & $20(29.4)$ & $16(25.4)$ & NA & 0.696 \\
\hline \multicolumn{4}{|l|}{ Methacholine challenge } & $\mathrm{PC} 20 \mathrm{mg} \cdot \mathrm{mL}^{-1}$ \\
\hline \multicolumn{5}{|l|}{ Baseline } \\
\hline Subjects n & 16 & 12 & & \\
\hline $\mathrm{PC}_{20}$ & $0.6(0.1-8)$ & $1.1(0.1-16)$ & & \\
\hline Week 12 & & & NA & 0.464 \\
\hline Subjects n & 9 & 12 & & \\
\hline $\mathrm{PC}_{20}$ & $2.0(0.1-16)$ & $1.0(0.1-32)$ & & \\
\hline \multicolumn{5}{|l|}{$A Q L Q$} \\
\hline \multicolumn{5}{|l|}{ Baseline } \\
\hline Subjects $n$ & 68 & 64 & & \\
\hline AQLQ score & $4.1 \pm 1.1$ & $4.3 \pm 1.3$ & & \\
\hline Week 12 & & & $0.3 \pm 0.2$ & $0.125^{\#}$ \\
\hline Subjects $n$ & 68 & 64 & & \\
\hline AQLQ score & $4.7 \pm 1.4$ & $4.6 \pm 1.4$ & & \\
\hline
\end{tabular}

Data are presented as mean \pm SD or geometric mean (range), unless otherwise stated. ETN: etanercept; PEF: peak expiratory flow; ACQ-5: Asthma Control Questionnaire (5-item version); PC20: provocative concentration causing a 20\% decrease in forced expiratory volume in $1 \mathrm{~S}$; AQLQ: Asthma Quality of Life Questionnaire; NA: not applicable. ${ }^{\#}$ : ANCOVA model change $=$ baseline + treatment group.

Treatment-emergent infections were reported in $30(44 \%)$ ETN subjects compared with $34(54 \%)$ placebo subjects; the most common treatment-emergent infection was respiratory tract infection (table 3). No significant difference in the incidence of any infection was shown between the ETN and placebo groups.

There was one serious noninfectious AE reported in the study. This was an anaphylactoid reaction that occurred in a subject in the ETN group and was temporally related to ETN 


\begin{tabular}{|c|c|c|c|}
\hline \multirow[t]{2}{*}{ TABLE 3} & \multicolumn{3}{|c|}{$\begin{array}{l}\text { Most frequent }(\geqslant 3 \%) \text { treatment-emergent } \\
\text { adverse events (AEs) }\end{array}$} \\
\hline & & ETN & Placebo \\
\hline \multirow{2}{*}{\multicolumn{2}{|c|}{$\begin{array}{l}\text { Subjects n } \\
\text { AEs }\end{array}$}} & 68 & 63 \\
\hline & & & \\
\hline \multicolumn{4}{|c|}{ Common noninfectious } \\
\hline \multicolumn{2}{|l|}{ Any ${ }^{\#}$} & $41(60.3)$ & $31(49.2)$ \\
\hline \multicolumn{2}{|c|}{ Injection site reaction } & $25(36.8)$ & $7(11.1)$ \\
\hline \multicolumn{2}{|c|}{ Headache } & $8(11.8)$ & $6(9.5)$ \\
\hline \multicolumn{2}{|c|}{ Migraine } & $4(5.9)$ & $2(3.2)$ \\
\hline \multicolumn{2}{|c|}{ Asthenia } & $4(5.9)$ & $1(1.6)$ \\
\hline \multicolumn{2}{|c|}{ Back pain } & $4(5.9)$ & $1(1.6)$ \\
\hline \multicolumn{2}{|c|}{ Cough increased } & $4(5.9)$ & $1(1.6)$ \\
\hline \multicolumn{2}{|c|}{ Accidental injury } & $3(4.4)$ & $3(4.8)$ \\
\hline \multicolumn{2}{|l|}{ Nausea } & $3(4.4)$ & $3(4.8)$ \\
\hline \multicolumn{2}{|l|}{ Myalgia } & $3(4.4)$ & $1(1.6)$ \\
\hline \multicolumn{2}{|c|}{ Chest pain } & $3(4.4)$ & $0(0.0)$ \\
\hline \multicolumn{2}{|l|}{ Rhinitis } & $3(4.4)$ & $2(3.2)$ \\
\hline \multicolumn{2}{|l|}{ Fever } & $2(2.9)$ & $2(3.2)$ \\
\hline \multicolumn{2}{|c|}{ Hypertension } & $2(2.9)$ & $4(6.3)$ \\
\hline \multicolumn{2}{|c|}{ Dyspnoea } & $1(1.5)$ & $2(3.2)$ \\
\hline \multicolumn{2}{|c|}{ Wheezing } & $0(0.0)$ & $3(4.8)$ \\
\hline \multicolumn{2}{|c|}{ Neck pain } & $0(0.0)$ & $2(3.2)$ \\
\hline \multicolumn{4}{|c|}{ Common infectious } \\
\hline \multicolumn{2}{|l|}{ Any } & $30(44.1)$ & $34(54.0)$ \\
\hline \multicolumn{2}{|c|}{ Upper respiratory } & $8(11.8)$ & $13(20.6)$ \\
\hline \multicolumn{2}{|c|}{ Bronchitis } & $7(10.3)$ & $7(11.1)$ \\
\hline \multicolumn{2}{|c|}{ Sinusitis } & 7 (10.3) & $4(6.3)$ \\
\hline \multicolumn{2}{|c|}{ Gastrointestinal } & $5(7.4)$ & $0(0.0)$ \\
\hline \multicolumn{2}{|c|}{ Influenza syndrome } & $4(5.9)$ & $5(7.9)$ \\
\hline \multicolumn{2}{|c|}{ Pharyngitis/laryngitis } & $4(5.9)$ & $5(7.9)$ \\
\hline \multicolumn{2}{|c|}{ Oropharygeal } & $3(4.4)$ & $3(4.8)$ \\
\hline \multicolumn{2}{|c|}{ Gingival/dental } & $3(4.4)$ & $1(1.6)$ \\
\hline Vaginitis & & $1(1.5)$ & $3(4.8)$ \\
\hline
\end{tabular}

Data are presented as $\mathrm{n}(\%)$, unless otherwise stated. ETN: etanercept. \#: excludes infections and asthma exacerbations.

administration (table 4). Subjects reporting serious or medically important infectious AEs are shown in table 4. The incidence of serious or medically important infections was not significantly different between treatments (ETN: two $(2.9 \%)$ subjects; placebo: five $(7.9 \%)$ subjects). No deaths or malignancies were reported during the 12-week study or during the 2-4 weeks of follow-up. Eight ETN subjects and three placebo subjects discontinued from the study because of AEs (fig. 1). Overall, ETN was well tolerated, and there were no unexpected safety findings in this study population.

\section{DISCUSSION}

This study evaluated the efficacy and safety of $25 \mathrm{mg}$ ETN administered twice weekly by subcutaneous injection in subjects with moderate-to-severe persistent asthma. ETN failed to demonstrate clinical efficacy on any of the clinical or lung function end-points in this study population of subjects who predominately had severe asthma. These findings contrast with those from earlier, smaller studies of various study

\begin{tabular}{|c|c|c|c|}
\hline \multirow[t]{2}{*}{ TABLE 4} & \multicolumn{3}{|c|}{$\begin{array}{l}\text { Subjects experiencing serious noninfectious and } \\
\text { infectious adverse events (AEs) }\end{array}$} \\
\hline & & ETN & Placebo \\
\hline Subjects $n$ & & 68 & 63 \\
\hline \multicolumn{4}{|l|}{ AEs } \\
\hline \multicolumn{4}{|c|}{ Serious noninfectious ${ }^{\#}$} \\
\hline Any & & $1(1.5)$ & $0(0.0)$ \\
\hline Anaphyl & oid reaction & $1(1.5)$ & $0(0.0)$ \\
\hline \multicolumn{4}{|c|}{ Serious and medically important infectious } \\
\hline Any & & $2(2.9)$ & $5(7.9)$ \\
\hline Acute di & ticulitis & $1(1.5)$ & $0(0.0)$ \\
\hline Meningit & & $1(1.5)$ & $0(0.0)$ \\
\hline Influenze & yndrome & $0(0.0)$ & $2(3.2)$ \\
\hline Cystitis & & $0(0.0)$ & $1(1.6)$ \\
\hline Lower re & iratory infection & $0(0.0)$ & $1(1.6)$ \\
\hline Bronchit & & $0(0.0)$ & $1(1.6)$ \\
\hline Otitis & & $0(0.0)$ & $1(1.6)$ \\
\hline
\end{tabular}

Data are presented as n (\%), unless otherwise stated. ETN: etanercept. ${ }^{*}$ : those that may result in death, are life-threatening, require subject hospitalisation or prolongation of an existing hospitalisation, or result in a persistent or significant disability or incapacity, cancer, or congenital anomaly or birth defect; ${ }^{\bullet}$ : those requiring hospitalisation or parenteral antibiotics.

designs, investigating the clinical efficacy of ETN in different asthmatic study populations, which showed that ETN was associated with significant improvements in asthma symptoms, airway hyperresponsiveness and quality of life [14, 23].

Although the negative findings from the present study are consistent with the results of other small placebo-controlled ETN trials reported by MORJARIA et al. [24] $(n=39 ; 12$-week study) and ROUHANI et al. [30] ( $\mathrm{n}=21 ; 2$-week study), and with the outcomes of controlled studies involving other anti-TNF agents, including infliximab for 8 weeks $(n=38)$ [3] and golimumab for 24 weeks $(n=309)$ [25], the current findings should be viewed in the context of the study design. First, it is important to note that the subjects included in this study were categorised as having moderate-to-severe asthma according to the NHLBI guidelines [27]. Therefore, the asthma in this population may not have been as severe as in other studies with ETN. However, in a randomised, placebo-controlled trial of 39 subjects with severe, corticosteroid-refractory asthma, no significant differences between 12 weeks of ETN or placebo were found for certain end-points, specifically, improvements in AQLQ scores, lung function, morning PEF, bronchial hyperresponsiveness or exacerbation rates [24]. In contrast to the study by MORJARIA et al. [24] and the present study, BERRY et al. [23] $(\mathrm{n}=20)$ reported that 10 weeks of ETN compared with placebo was associated with an improvement in PC20, AQLQ and post-bronchodilator FEV1 in subjects with refractory asthma. Furthermore, the subjects in the current study demonstrated less airway hyperresponsiveness to methacholine at baseline than those studied by BERRY et al. [23], and also HOWARTH et al. [14], who had reported asthma-symptom improvements with 12 weeks of ETN in an open-label, uncontrolled study. Taken together, these observations suggest that, given the heterogeneous nature of asthma, the severity of 
the disease may be critical in data analysis and interpretation. Furthermore, selection of patients with noneosinophilic asthma may have yielded different results, as patients with eosinophilic asthma had reduced levels of TNF from sputum cells relative to those in patients with noneosinophilic asthma [31].

Secondly, the short-term follow-up of 12 weeks may not have been adequate to observe a clinically significant response with ETN in this particular study population. Studies with longer term follow-up may be required. Additionally, this 12-week study was too short to observe any malignancies with etanercept. However, eight malignancies were previously reported by WENZEL et al. [25] in a 76-week safety analysis of golimumab treatment in 309 patients with severe persistent asthma.

Thirdly, the study lacked biochemical analyses of TNF- $\alpha$ or other clinically important biomarkers. In the study by BERRY et al. [23], expression of membrane-bound TNF- $\alpha$ on peripheral blood mononuclear cells correlated with responsiveness to ETN. In hindsight, a similar analysis of TNF- $\alpha$ status might have provided a biomarker of responsiveness to ETN. This biomarker approach to subphenotyping of severe asthma has recently been successful in identifying responders to the anti-interleukin-5 monoclonal antibody mepolizumab, using sputum eosinophilia, despite the use of high-dose corticosteroids as an enrolment criterion [8, 9]. However, in another study of an unselected population of patients with severe asthma, mepolizumab was found to be ineffective [32].

In the present study, standard analyses were used to evaluate lung function, symptoms and airway responsiveness in patients with asthma. Based on the results from the recent study of golimumab showing possible benefits among subjects with FEV1 reversibility $>12 \%$ at baseline, we attempted to analyse our data in a similar manner. Because we required FEV1 reversibility of $\geqslant 9 \%$ during the screening period for subject eligibility, there were only seven ETN and 10 placebo subjects with FEV1 reversibility $<12 \%$, so we analysed our data by FEV1 reversibility tertiles. However, these analyses showed no significant difference between ETN and placebo for FEV1 reversibility by tertile subgroup $(\leqslant 16 \%,>16 \%$ and $\leqslant 24 \%$, and $>24 \%$ improvement from pre-bronchodilator FEV1 \% pred at baseline). Severe corticosteroid refractory asthma is characterised by reduced bronchodilator reversibility, possibly as a consequence of airway wall remodelling [33, 34]. It remains possible that selection of patients on the basis of greater bronchodilator response and/or bronchial hyperresponsiveness might have revealed some efficacy.

With regard to safety, no unexpected findings were observed during this study. ETN was shown to be a well-tolerated therapy. The occurrence of infections in this study was similar to that observed in previous studies examining the efficacy of ETN in subjects with asthma [3, 14]. These safety findings are consistent with the favourable safety profile associated with the long-term administration of $25 \mathrm{mg}$ ETN twice weekly for other indications. However, in a 24-week study that included $\leqslant 76$ weeks of follow-up, subjects with severe asthma treated with golimumab had a significantly higher rate of infection than those in the placebo arm [25]. One possible explanation for the lower infection rate with ETN than with other antiTNF- $\alpha$ monoclonal antibodies may be the lesser binding affinity of ETN for membrane-bound TNF- $\alpha$ as compared with that of the monoclonal antibodies. This may prevent or lessen the rate of apoptosis of immunocompetent cells [35, 36]. A previous report showed that infliximab and adalimumab, but not ETN, induced apoptosis and cell-cycle arrest in T-cells transfected with transmembrane TNF- $\alpha$ [37]. These findings suggest that different anti-TNF- $\alpha$ therapies have different biologic effects on transmembrane TNF- $\alpha$. Additional studies are needed to fully characterise the differences in the mechanisms of the anti-TNF- $\alpha$ therapies.

In conclusion, the safety profile for ETN in subjects with moderate-to-severe persistent asthma is similar to that seen in subjects with other inflammatory diseases, such as rheumatoid arthritis, ankylosing spondylitis, psoriasis and psoriatic arthritis [38-41]. Considering the efficacy findings from this study as well as from the studies with golimumab and infliximab, it seems unlikely that asthma will be among the chronic inflammatory disorders for which TNF blockade is indicated. Although there is ample evidence that TNF- $\alpha$ is generated in asthmatic airways, its role in disease causation is questionable. Nonetheless, this may not exclude a small subgroup of subjects with asthma in whom TNF- $\alpha$ may play a prominent role. Future studies are warranted to investigate the role of TNF blockade in the aetiology of asthma and to gain a better understanding of the specific asthmatic study population suitable for TNF- $\alpha$ therapy.

\section{SUPPORT STATEMENT}

This study was sponsored by Wyeth, which was acquired by Pfizer Inc. in October 2009. Medical writing support for this manuscript was provided by C. Bradley (Precise Publications LLC, Pluckemin, NJ, USA) and was funded by Wyeth.

\section{CLINICAL TRIAL}

This study is registed at ClinicalTrials.gov with identifier number NCT00141791.

\section{STATEMENT OF INTEREST}

Statements of interest for S.T. Holgate, M. Noonan, P. Chanez, I. Pavord, A. Hakulinen, L. Paolozzi, J. Wadjula, C. Zang, H. Nelson, D. Raible and the study itself can be found at www.erj.ersjournals. $\mathrm{com} / \mathrm{site} / \mathrm{misc} /$ statements.xhtml

\section{ACKNOWLEDGEMENTS}

Medical writing support for this manuscript was provided by C. Bradley (Precise Publications LLC, Pluckemin, NJ, USA) and was funded by Wyeth, which was acquired by Pfizer Inc. in October 2009. The authors thank the other investigators who participated in the study: R. Niven (Wythenshawe Hospital, Manchester, UK), B. Higgins (Sir William Leech Centre, Freeman Hospital, Newcastle upon Tyne, UK), S.H. Arshad (University Hospital of North Staffordshire, Stokeon-Trent, UK), R. Makitaro (Oulu University Hospital, Oulu, Finland), S. Saarelainen (Tampere University Hospital, Pikonlinna, Finland), G. Stalenheim (Lungkliniken, Dept of Pulmonary Disease, Uppsala, Sweden), R. Louis (Centre Hospitalier Universitaire de Liege, Sart Tilman, Belgium), M. Daenen (Erasmus, Genk, Belgium), Hendrich Timmer (Streekziekenhuis Midden Twente, Hengelo, the Netherlands), M. Aubier (Hôpital Bichat, Centre d'Investigation Clinique, Paris, France), P. Chanez (Hôpital Arnaud de Villeneuve, Montpellier, France), M. Humbert (Hopital Antoine Béclère, Clamart, France), J. Schul (Virginia Adult and Pediatric Allergy and Asthma PC, Richmond, VA, USA), A. Halsey (Brandon-Valico Center for Allergy and Asthma Research LLC, Valrico, FL, USA), R. Saff (Allergy and 
Asthma Diagnostic Treatment Center, Tallahassee, FL, USA), M. White (Institute for Asthma and Allergy, Wheaton, MD, USA), H. Windom (Adult and Peadiatric Allergy, Sarasota, FL, USA), S. Goldstein (Allergy and Asthma Care of Long Island, Commack, NY, USA), I. Tillie-Leblond (Hôpital Albert Calmette, Lille, France), G. Serfilippi (Pulmonary and Critical Care Services PC, Albany, NY, USA), J. Gluck (Florida Center for Allergy and Asthma Research, Miami, FL, USA), M. Tarpay (Allergy and Asthma Center, Oklahoma City, OK, USA), D. Cypcar (Regional Allergy and Asthma, Asheville, NC, USA), K. Drain (Spokane Allergy and Asthma Clinic, Spokane, WA, USA), T. Lee (Peachtree Allergy and Asthma Clinic PC, Atlanta, GA, USA), B. Goodman (Aero Allergy Research Labs of Savannah Inc., Savannah, GA, USA), J. Given (Allergy and Respiratory Center, Canton, OH, USA) and J. Corren (Allergy Medical Clinic, Los Angeles, CA, USA).

Permission to use the ACQ-5 was kindly provided by E.F. Juniper (Qoltech, Bosham, UK).

\section{REFERENCES}

1 Moore WC, Peters SP. Severe asthma: an overview. J Allergy Clin Immunol 2006; 117: 487-494.

2 Holgate ST, Holloway J, Wilson S, et al. Understanding the pathophysiology of severe asthma to generate new therapeutic opportunities. J Allergy Clin Immunol 2006; 117: 496-506.

3 Erin EM, Leaker BR, Nicholson GC, et al. The effects of a monoclonal antibody directed against tumor necrosis factor- $\alpha$ in asthma. Am J Respir Crit Care Med 2006; 174: 753-762.

4 Steinke JW, Borish L. 3. Cytokines and chemokines. J Allergy Clin Immunol 2006; 117: S441-S445.

5 Antonicelli L, Bucca C, Neri M, et al. Asthma severity and medical resource utilisation. Eur Respir J 2004; 23: 723-729.

6 Godard P, Chanez P, Siraudin L, et al. Costs of asthma are correlated with severity: a 1-yr prospective study. Eur Respir J 2002; 19: 61-67.

7 Serra-Batlles J, Plaza V, Morejon E, et al. Costs of asthma according to the degree of severity. Eur Respir J 2009; 12: 1322-1326.

8 Haldar P, Brightling CE, Hargadon B, et al. Mepolizumab and exacerbations of refractory eosinophilic asthma. N Engl J Med 2009; 360: 973-984.

9 Nair P, Pizzichini MM, Kjarsgaard M, et al. Mepolizumab for prednisone-dependent asthma with sputum eosinophilia. $N$ Engl J Med 2009; 360: 985-993.

10 Shah A, Church MK, Holgate ST. Tumour necrosis factor alpha: a potential mediator of asthma. Clin Exp Allergy 1995; 25: 1038-1044.

11 Ito $\mathrm{T}$, Wang YH, Duramad O, et al. TSLP-activated dendritic cells induce an inflammatory $\mathrm{T}$ helper type 2 cell response through OX40 ligand. J Exp Med 2005; 202: 1213-1223.

12 Keatings VM, Jatakanon A, Worsdell YM, et al. Effects of inhaled and oral glucocorticoids on inflammatory indices in asthma and COPD. Am J Respir Crit Care Med 1997; 155: 542-548.

13 Obase Y, Shimoda T, Mitsuta K, et al. Correlation between airway hyperresponsiveness and airway inflammation in a young adult population: eosinophil, ECP, and cytokine levels in induced sputum. Ann Allergy Asthma Immunol 2001; 86: 304-310.

14 Howarth PH, Babu KS, Arshad HS, et al. Tumour necrosis factor $(\mathrm{TNF} \alpha)$ as a novel therapeutic target in symptomatic corticosteroid dependent asthma. Thorax 2005; 60: 1012-1018.

15 Azevedo I, de Blic J, Dumarey $\mathrm{CH}$, et al. Increased spontaneous release of tumour necrosis factor- $\alpha$ by alveolar macrophages from wheezy infants. Eur Respir J 1997; 10: 1767-1773.

16 Hallsworth MP, Soh CP, Lane SJ, et al. Selective enhancement of GM-CSF, TNF- $\alpha$, IL-1 $\beta$ and IL- 8 production by monocytes and macrophages of asthmatic subjects. Eur Respir J 1994; 7: 1096-1102.

17 Thomas PS, Yates DH, Barnes PJ. Tumor necrosis factor- $\alpha$ increases airway responsiveness and sputum neutrophilia in normal human subjects. Am J Respir Crit Care Med 1995; 152: 76-80.
18 Thomas PS, Heywood G. Effects of inhaled tumour necrosis factor alpha in subjects with mild asthma. Thorax 2002; 57: 774-778.

19 Casale TB, Costa JJ, Galli SJ. TNF alpha is important in human lung allergic reactions. Am J Respir Cell Mol Biol 1996; 15: 35-44.

20 Thomas PS. Tumour necrosis factor- $\alpha$ : the role of this multifunctional cytokine in asthma. Immunol Cell Biol 2001; 79: 132-140.

21 Vilcek J, Feldmann M. Historical review: cytokines as therapeutics and targets of therapeutics. Trends Pharmacol Sci 2004; 25: 201-209.

22 Weinblatt ME, Kremer JM, Bankhurst $\mathrm{AD}$, et al. A trial of etanercept, a recombinant tumor necrosis factor receptor: FC fusion protein, in patients with rheumatoid arthritis receiving methotrexate. N Engl J Med 1999; 340: 253-259.

23 Berry MA, Hargadon B, Shelley M, et al. Evidence of a role of tumor necrosis factor $\alpha$ in refractory asthma. N Engl J Med 2006; 354: 697-708.

24 Morjaria JB, Chauhan AJ, Babu KS, et al. The role of a soluble TNF $\alpha$ receptor fusion protein (etanercept) in corticosteroid refractory asthma: a double blind, randomised, placebo controlled trial Thorax 2008; 63: 584-591.

25 Wenzel SE, Barnes PJ, Bleecker ER, et al. A randomized, doubleblind, placebo-controlled study of tumor necrosis factor- $\alpha$ blockade in severe persistent asthma. Am J Respir Crit Care Med 2009; 179: 549-558.

26 Chanez P, Wenzel SE, Anderson GP, et al. Severe asthma in adults: what are the important questions? J Allergy Clin Immunol 2007; 119: 1337-1348.

27 National Heart, Lung and Blood Institute. Expert Panel Report 2. Guidelines for the diagnosis and management of asthma. NIH Publication No 97-4051. Bethesda, NIH, 1997.

28 Juniper EF, O'Byrne PM, Guyatt GH, et al. Development and validation of a questionnaire to measure asthma control. Eur Respir $J$ 1999; 14: 902-907.

29 Juniper EF, Buist AS, Cox FM, et al. Validation of a standardized version of the Asthma Quality of Life Questionnaire. Chest 1999; 115: 1265-1270.

30 Rouhani FN, Meitin CA, Kaler M, et al. Effect of tumor necrosis factor antagonism on allergen-mediated asthmatic airway inflammation. Respir Med 2005; 99: 1175-1182.

31 Quaedvlieg V, Henket M, Sele J, et al. Cytokine production from sputum cells in eosinophilic versus non-eosinophilic asthmatics. Clin Exp Immunol 2005; 143: 161-166.

32 Flood-Page P, Swenson C, Faiferman I, et al. A study to evaluate safety and efficacy of mepolizumab in patients with moderate persistent asthma. Am J Respir Crit Care Med 2007; 176: 1062-1071.

33 ten Brinke A, Zwinderman AH, Sterk PJ, et al. Factors associated with persistent airflow limitation in severe asthma. Am J Respir Crit Care Med 2001; 164: 744-748.

34 Kaminska M, Foley S, Maghni $\mathrm{K}$, et al. Airway remodeling in subjects with severe asthma with or without chronic persistent airflow obstruction. J Allergy Clin Immunol 2009; 124: 45-51.

35 Van Den Brande JM, Braat H, Van Den Brink GR, et al. Infliximab but not etanercept induces apoptosis in lamina propria Tlymphocytes from patients with Crohn's disease. Gastroenterology 2003; 124: 1774-1785.

36 Mitoma H, Horiuchi $\mathrm{T}$, Tsukamoto $\mathrm{H}$. Binding activities of infliximab and etanercept to transmembrane tumor necrosis factor- $\alpha$. Gastroenterology 2004; 126: 934-935.

37 Mitoma $\mathrm{H}$, Horiuchi $\mathrm{T}$, Tsukamoto $\mathrm{H}$, et al. Mechanisms for cytotoxic effects of anti-tumor necrosis factor agents on transmembrane tumor necrosis factor alpha-expressing cells: comparison among infliximab, etanercept, and adalimumab. Arthritis Rheum 2008; 58: 1248-1257.

38 Van Der Heijde D, Klareskog L, Rodriguez-Valverde V, et al. Comparison of etanercept and methotrexate, alone and combined, in the treatment of rheumatoid arthritis: two-year clinical and radiographic results from the TEMPO study, a double-blind, randomized trial. Arthritis Rheum 2006; 54: 1063-1074. 
39 Van Der Heijde D, Da Silva JC, Dougados M, et al. Etanercept $50 \mathrm{mg}$ once weekly is as effective as $25 \mathrm{mg}$ twice weekly in patients with ankylosing spondylitis. Ann Rheum Dis 2006; 65: 1572-1577.

40 Saad AA, Ashcroft DM, Watson KD, et al. Persistence with antitumour necrosis factor therapies in patients with psoriatic arthritis: observational study from the British Society of Rheumatology Biologics Register. Arthritis Res Ther 2009; 11: R52.

41 Barrera MV, Habicheyn S, Mendiola MV, et al. Etanercept in the treatment and retreatment of psoriasis in daily clinical practice. Eur J Dermatol 2008; 18: 683-687. 